\title{
Bolaño: el espejo roto de sí mismo (o los nombres de los viajes y el exilio)
}

\author{
Juan Carlos Pino-Correa ${ }^{1}$ \\ Universidad del Cauca, Colombia
}

\begin{abstract}
Resumen: Esta reflexión se constituye en una exploración sobre las transformaciones, la disolución y la reconfiguración del concepto de territorio en la obra del escritor chileno Roberto Bolaño. El lugar de la infancia, las relaciones intertextuales y los contactos con otros universos idiomáticos son los tres aspectos que se abordan aquí y que enfatizan en la ruptura literaria de diversas fronteras como una forma de reconstruir un rostro y una identidad pero que también pueden leerse como una forma del exilio.
\end{abstract}

Palabras clave: Bolaño; exilio; infancia; intertextualidad; territorio.

Recibido: 21 de agosto de 2019

Aprobado: 17 de octubre de 2019

\section{Bolaño: the broken mirror of himself (or the names of the voyages and the exile)}

\begin{abstract}
This paper is an exploration about the transformations, the dissolution and the reconfigurations of the concept of territory in the Roberto Bolaño's work. The place of childhood, the intertextual relations and the contacts with other idiomatics worlds are the subjects exposed here. This mentioned subject emphasizes in the literary rupture of boundaries as a way to reconstruct a face and an identity but also can be read as a form of exile.
\end{abstract}

Keywords: Bolaño; childhood; exile; intertextuality; territory.

\section{Introducción}

Es posible afirmar que en los múltiples y variados desplazamientos contemporáneos, en los diversos saltos al vacío, en las inevitables errancias, en las complejas desterritorializaciones y reterritorializaciones, en los eternos retornos (no precisamente físicos), la literatura latinoamericana ha encontrado un nuevo aire, una posmoderna decantación, una manera de asumir sin complejos el franqueo de fronteras e, incluso, sin culpas ni traumas los exilios. Tal situación ha hecho que algunos escritores intenten desestigmatizar este término y darle una resignificación que sustente de alguna medida sus trashumancias físicas y literarias.

\footnotetext{
1Juan Carlos Pino Correa (Almaguer, Colombia, 1968). Comunicador Social, Abogado y Doctor en Investigación en Artes y Humanidades, actualmente se desempeña como profesor titular del Departamento de Comunicación Social de la Universidad del Cauca, donde hace parte del grupo de investigación Estudios Culturales y de la Comunicación y dirige el Laboratorio de Medios Periodísticos Comarca. Ha publicado los libros de viaje Mirada al Sur: travesías por territorios de niebla y Hacer camino en La Mancha: memorias breves y estampas cotidianas, así como las novelas Hojas sin nombre, Los habitados, Noche de fusiles, No solo la noche es oscura y La piel sagrada, además del libro de relatos Los escaques y la noche. Correo electrónico: jcpino@unicauca.edu.co
} 
Roberto Bolaño, por ejemplo, considera el exilio como el valor real que cada escritor tiene y descree de él en ciertos ámbitos, como en la literatura. "El exilio es una cuestión de gustos, caracteres, filias, fobias. Para algunos escritores exiliarse es abandonar la casa paterna, para otros abandonar el pueblo o la ciudad de la infancia, para otros, más radicalmente, crecer. Hay exilios que duran toda una vida y otros que duran un fin de semana." (Entre paréntesis 50) Aquí entonces es donde puede ahondarse en las inquietudes que Bolaño tiene con el concepto de tierra extraña y donde se pregunta si el concepto se refiere a una realidad objetiva y geográfica u obedece a una construcción mental que no está quieta jamás. Por eso su descreimiento en la palabra, en lo que implica el concepto como tal, y por eso el ensanchamiento del sentido de tal término, y más si se lo relaciona con la literatura.

Probablemente todos, escritores y lectores, empezamos nuestro exilio, o al menos un cierto tipo de exilio, al dejar atrás la infancia. Lo que llevaría a concluir que el ente exiliado, la categoría exiliado, sobre todo en lo que respecta a la literatura, no existe. Existe el inmigrante, el nómade, el viajero, el sonámbulo, pero no el exiliado, puesto que todos los escritores, por el solo hecho de asomarse a la literatura lo son, y todos los lectores, ante el solo hecho de abrir un libro, también lo son. (51)

El exilio, en la medida en que denota abandono de una tierra para reposicionarse en otra, implica movilidad, refundación, re-nacimiento. Y los desplazamientos son muchos: moverse de la patria de la infancia a la de la adolescencia, o de los territorios de una obra a la de otra, o entrar en zona de contacto con otro mundo idiomático. De estas tres travesías se hablará en este artículo, aunque también haya algunas más: cruzar las fronteras que aparentemente dividían un género literario de otro, o narrar historias donde se hibriden lo real, que puede ser autobiográfico, y lo inventado, o romper por fin las barreras monolíticas de una tradición nacional para entrar de lleno en la tradición universal.

Es posible que, en algunas ocasiones, el exilio implique violencia, así ésta no sea física. Pero también es posible que, en otras, el exilio sea una elección personal, una búsqueda de nuevos horizontes que pronto se ve reflejada en las historias y los relatos que cada escritor construye y comparte. En uno y otro caso es esencial el derrumbamiento de fronteras, cualesquiera que éstas sean e independiente de cómo se las perciba. Aquí, bien se puede decir, con Michel de Certeau, que el relato configura una lógica de la ambigüedad y "convierte la frontera en travesía, y el río en puente" (140). El exilio se convierte entonces en sentido de vida y el no lugar en lugar, por la necesidad de explorar, como diría el escritor ecuatoriano Leonardo Valencia, los territorios impuros, que no son los territorios ajenos, ni mucho menos, sino aquellos que conducen a "acercarnos creativamente a conocer la naturaleza subjetiva del hombre en diversos sitios, donde sea que esté" (186). La impureza se entiende aquí como sentido esencial, no como pecado; la impureza como devenir de los hombres en diversos espacios, en múltiples encuentros y desencuentros, en inesperadas interacciones. Mundos diversos que se juntan y se conocen y reconocen, y se reconfiguran. Mundos que se construyen y reconstruyen en diversas zonas de contacto entendidas éstas como escenarios de encuentros y de cruces entre diversos sujetos en un momento histórico determinado. Mundos donde la cultura se 
muestra como escenario principal de las diversas actuaciones de los seres humanos. De aquellos mundos bolañianos se hace necesario realizar al menos un breve perfil que dé cuenta de la magnitud de sus dimensiones y de su proyección.

\section{Venir de la patria secreta de la infancia}

Se había dicho, antes, que la infancia como patria configura en la literatura un territorio, más que un espacio temporal. Son muchos los autores que lo plantean de tal manera. En la obra de Roberto Bolaño, es importante destacar una cierta ausencia de referentes a la infancia en el mundo de Arturo Belano, el alter ego del escritor, y en otros personajes fundamentales y paradigmáticos. Pareciera que ese paraíso perdido de la infancia quiere guardárselo como un secreto, como una reliquia individual que no debe ser conocida por los demás una vez se ha entrado ya en las entrañas caóticas de la adolescencia y las edades posteriores, donde no hay duda en acoger la opción de ser un guerrero de las guerras floridas latinoamericanas, como él mismo suele decir. Su silencio es como mantener vigente su autoexilio del territorio de la infancia. "Hay cosas que se pueden contar y hay cosas que no se pueden contar, piensa B. abatido" (Putas asesinas 54), recién llegado a México. Y por eso, se sabe tan poco del espejo roto que configura el rostro del B. de la infancia, del Belano de la infancia (o del Bolaño de la infancia). Se sabe que recorría las carreteras del sur de Chile en el viejo camión de su padre y que él le compró a B, cuando tenía siete años, un caballo que se llamaba Zafarrancho, y se sabe que su madre les leía, “en Quilpué, en Cauquenes, en Los Ángeles”, Veinte poemas de amor y una canción desesperada. "Los Veinte poemas, mis Veinte poemas, han recorrido un largo camino. Primero por diversos pueblos del sur de Chile, después por varias casas de México D.F., después por tres ciudades de España.” (207).

Se sabe eso de Bolaño y poco más (que le gustaba el fútbol y disfrutó del Mundial del 62 en Chile y le encantaba coleccionar láminas de jugadores y de actrices, y que tenía unos patines), como si fuera un sacrilegio revelar algún otro detalle. Pero eso no impide imaginarlo haciendo evocaciones en silencio porque los recuerdos de ese territorio están ahí, ubicuos siempre, su presencia es evidente, aunque el velo que los cubre no se corra casi nunca. Un silencio que se parece al autoexilio, pese a que Bolaño no cree haberlo habitado o haberse dejado habitar por él: "Nunca he estado en el autoexilio. La palabra es bastante reductora. En autoexilio podemos estar viviendo en Los Ángeles o en Mulchén. El autoexilio es un ocultamiento voluntario, es buscar la invisibilidad voluntariamente, y eso se puede hacer en tu propia casa" (Bolaño cit. Braithwaite 110). Sí, el autoexilio del territorio de la infancia puede ser para un escritor el silencio, bien sea en lo autobiográfico o en lo autoficcional. La casa que es la literatura, así como los libros propios y ajenos, asumen un silencio protector sobre aquel territorio que bien pudo haber sido un paraíso que a lo mejor devenía poco a poco en purgatorio y amenazaba con infierno, y que el viaje a México pretendía recomponer, aun a sabiendas de que el viaje, bien sea en la realidad o en la literatura, no tiene retorno. Dejar atrás Chile era abandonar de una vez y para siempre el territorio de la infancia y empezar a forjar un espíritu que, en el futuro, pudiera sentir nostalgia no de los territorios que se habían habitado en el pasado sino de aquellos que ni siquiera se conocían, como un ineludible paso al frente, como un eterno salto hacia el vacío, hacia lo desconocido, donde no haya "deseos de 
tribu". Bolaño no cree en el autoexilio pero sí en el exilio, entendido éste, según sus propias palabras, como una bendición para el escritor, como la quintaesencia de todo viaje, como la perfección de la escritura. Bolaño, como Belano, empieza a escribir a partir de los dieciséis. Para entonces, el territorio de la infancia ya había quedado atrás. Y el exilio comenzaba. Aunque, Carlos Franz advierta lo contrario: que, pese a todo, Bolaño nunca se fue de Chile:

Por muy expatriado que fuera, algo de B. nunca salió de la ciudad de Los Ángeles (tan lejos de los otros de California), cerca de la Araucanía de Chile. Nunca se libró de los horrorosos "ángeles" del resentimiento chileno. Lo que hizo, en cambio fue derrotar su silencio; darles una voz que se oyera muy lejos. Una voz como un incendio en esos bosques, envuelta en llamas (109).

\section{Un paseo por la literatura o los referentes intertextuales}

En Tres, Roberto Bolaño tiene un poema titulado Un paseo por la literatura. Es un texto donde se construye una interacción del hablante con artistas tutelares que bien se aparecen en sus sueños o se muestran en las calles de alguna gran ciudad. Allí hay encuentros con George Perec y Alonso de Ercilla, con Manuel Puig y Macedonio Fernández, con Efraín Puerta y Enrique Lihn, con Sthendal y Thomas de Quincey, con Aloysius Bertrand y Gui Rosey, con Archibald McLeish y los hermanos Goncourt, con Gabriela Mistral y Philip K. Dick, con Arquíloco y Nicanor Parra, con Vallejo y Martín Adán, con Virgilio y Paulin Joachim, con Franz Kafka y Mario de Sá-Carneiro, con Anacreonte y Mark Twain, con Alice Sheldon y Anaïs Nin, con Carson McCullers y Alphonse Daudet, con Robert Desnos y Roque Dalton, con Walt Whitman y Boecio, con el Marqués de Sade y Baudelaire, con Marcel Schwob y un escritor ruso, con James Mathew Barrie y de nuevo con George Perec.

La esencia del poema es moverse por todos los territorios literarios sin ningún tipo de complejo, sin ninguna barrera que detenga al hablante, que es el propio Bolaño, con el fin de establecer un diálogo con muchos escritores y de asumir para sí una tradición universal que siente propia porque las imágenes de aquellos escritores se proyectan sobre escenas absolutamente cotidianas, sin que puedan ni quieran parecer forzadas ni salidas de tono. Solo fluyen sin cesar, sin parar, con la naturalidad de los minutos y las horas de cada día, con la placidez de quien da un paseo pausado y seguro, con la elocuencia de los sueños bien soñados que, pese a lo que proyecten, no se consideran pesadillas: "Soñé que era un detective viejo y enfermo y que buscaba gente perdida hace tiempo. A veces me miraba casualmente en un espejo y reconocía a Roberto Bolaño.” (Tres 75)

Ese reconocimiento de Bolaño en la literatura no contrasta con otro reconocimiento que es, si no contrario, al menos ajeno a la literatura: la consciencia de venir de unas familias paterna y materna que arrastraban con ellas, como lo dice el propio autor chileno, quinientos años de analfabetismo constante y riguroso y trescientos de desidia constante y rigurosa. En eso podría parecerse un poco a Albert Camus, de cuya infancia se puede saber, a través de su novela El primer hombre (1994), el destino que como aprendiz de algún oficio le tenía reservado su familia extremadamente humilde y desheredada, destino del cual él supo sustraerse justo con todo aquello que sus seres queridos ni siquiera alcanzaban a vislumbrar ni a entender en la Argelia natal. O podría parecerse también, en 
ese mismo aspecto, a José Saramago, quien confiesa que el hombre más sabio que conoció era su abuelo, pese a que, como lo manifiesta al inicio de su discurso Nobel de 1998, ni siquiera sabía leer ni escribir y criaba cerdos con su esposa en la aldea portuguesa de Azinhaga (192).

En Bolaño, la genealogía familiar de analfabetismo y desidia se trunca para convertirse, entre otras muchas cosas, en intertextualidad, entendida ésta, con Genette ${ }^{2}$, "como la relación de copresencia entre dos o más textos, es decir, eidéticamente y frecuentemente, como la presencia efectiva de un texto en otro" $(10)^{3}$. Bolaño construye así un universo de libros - libros de todos los siglos, de todos los géneros y de todos los países-, como si estuviera asumiendo el exquisito lastre de leer aquellos que nadie más en su casa había leído nunca para después colocarlos con tacto en los libros propios, en los ya escritos o en los por escribir. O como si estuviera leyendo los libros que no sólo su familia no lee sino que la mayoría de latinoamericanos no lee, embebidos en historias audiovisuales más livianas e intrascendentes. En ese universo literario particular los protagonistas suelen ser personas letradas que también escriben libros y citan en ellos los libros que otros han escrito. Libros que existen en la realidad o que son sólo una ficción. ¿Qué más da! Se puede traer a colación, entonces, lo que Patricia Espinosa dice respecto de Un paseo por la literatura: "La cita, el nombre, la persona como pre-texto histórico se tematiza como un espacio en el que se cruza realidad y ficción, realidad y sueño, vida personal y vida literaria" (173). Concluye Espinosa que, con todo esto, "Bolaño asume la crisis de identidad que impone el paradigma posmoderno" (173), con la salvedad deque, en América Latina, más que hablar de posmodernidad debe hablarse de post-devastación y que en ese entorno la única seguridad posible es la escritura de la propia crisis.

En ese escenario, la utilización y la referencia a espejos constituye un símbolo de reconocimiento tanto como una manera de mostrar los propios desconocimientos de sí mismo: el miedo a lo que otros son o a lo que uno es y uno mismo desconoce. A Liz Norton, un personaje de 2666, le sucede eso: "Sintió miedo y curiosidad y permaneció

\footnotetext{
${ }^{2}$ Es importante recordar que el concepto de intertextualidad fue usado por primera vez por Julia Kristeva en 1967, con base en las lecturas y reflexiones que había hecho de Mijail Bajtin y del concepto de dialogicidad propuesto por el intelectual ruso. Kristeva señalaba que "todo texto se construye como un mosaico de citas, todo texto es absorción y transformación de otro texto" (190). Posteriormente el término tuvo nuevos desarrollos entre los que se destacan los realizados por Gérard Genette que dieron lugar a lo que se llamó la narratología.

${ }^{3}$ En Palimpsestos. La literatura en segundo grado (10-17), el teórico francés hace una clasificación de cinco tipos de relaciones transtextuales (o trascendencia textual del texto) que, en una perspectiva amplia, tienen generalmente comunicaciones entre sí y entrelazamientos recíprocos: 1) La intertextualidad, en la definición ya mencionada. 2) La relación que en el todo de la obra tiene el texto con el paratexto (título, subtítulo, intertítulo, prefacio, epígrafes, prólogos, pies de página, ilustraciones y demás señales accesorias). 3) La metatextualidad, o "relación — generalmente denominada «comentario»— que une un texto a otro texto que habla de él sin citarlo (convocarlo), e incluso, en el límite, sin nombrarlo" (13). 4) La hipertextualidad, entendida como "toda relación que une un texto B (que llamaré hipertexto) a un texto anterior A (al que llamaré hipotexto) en el que se injerta de una manera que no es el comentario" (14). Genette también define el hipertexto como "todo texto derivado de un texto anterior por transformación simple (diremos en adelante transformación sin más) o por transformación indirecta, diremos imitación" (17). 5) La architextualidad que "se trata de una relación completamente muda que, como máximo, articula una mención paratextual (títulos, como en Poesías, Ensayos, Le Roman de la Rose, etc., o, más generalmente, subtítulos: la indicación Novela, Relato, Poemas, etc., que acompaña al título en la cubierta del libro), de pura evidencia taxonómica. Cuando no hay ninguna mención, puede deberse al rechazo de señalar una evidencia o, al contrario, para recusar o eludir cualquier clasificación” (13).
} 
quieta, observando si cabe con mayor detenimiento a la figura del espejo. Objetivamente, se dijo, es igual a mí y no tengo ninguna razón para pensar lo contrario. Soy yo.” (Bolaño 154) Pero no es la única figura en la obra de Bolaño que muestra una actitud contemplativa y vacilante frente al espejo de los reconocimientos, pues en el cuento titulado "Detectives", contenido en el libro Llamadas telefónicas, se expone cómo Belano no se reconoce en el espejo de una comisaría de Chile apenas Pinochet ha dado el golpe. "Eso le dije yo, ¿y qué?, ¿eres tú o no eres tú? Y él entonces me miró a los ojos y me dijo: es otro, compadre, no hay remedio" (131). O lo que le sucede al sacerdote de Nocturno de Chile: "Al ponerle azúcar al té vi mi rostro reflejado en la superficie. ¿Quién te ha visto, Sebastián, y quién te ve?, me dije." (108).

En el camino de la escritura intertextual que construye y recorre Bolaño, Un paseo por la literatura es apenas una manera de ratificar, en la poesía, un elemento de su obra que está presente en la totalidad de su narrativa, principalmente en Los detectives salvajes (publicada inicialmente en 1998). El hecho mismo de que esta novela trate sobre los poetas vinculados al grupo del real visceralismo, que tiene como referente al infrarrealismo mexicano de los setenta, inspirado en el estridentismo de los años veinte, permite que el mundo de la intertextualidad campee a sus anchas a través de la novela de una forma transversal y en diferentes modalidades. No es sólo la mención de autores consagrados de la época, como Octavio Paz o Efraín Huerta, sino de todos aquellos, unos más conocidos que otros, que se constituyen en los referentes ineludibles de los jóvenes contestatarios liderados por Arturo Belano y Ulises Lima, de cuya obra, al igual que la de la poeta que buscan desesperadamente, nunca es posible conocer nada textual.

Al llegar junto a él me pareció que no estaría de más hacer una presentación formal, así que dije: don Octavio Paz, el poeta real visceralista Ulises Lima. Y entonces don Octavio, al tiempo que invitaba al tal Lima a tomar asiento, dijo: real visceralista, real visceralista (como si el nombre le sonara de algo), ¿no fue ese el grupo poético de Cesárea Tinajero? Y el tal Lima se sentó junto a don Octavio y suspiró o hizo un ruido raro con los pulmones y dijo sí, así se llamaba el grupo de Cesárea Tinajero. Durante un minuto o algo así estuvieron callados, mirándose. Un minuto bastante insoportable, si he de ser sincera. (Bolaño, Los detectives salvajes 509).

La referencia a Octavio Paz, aquí, es un encuentro de nuevo con el establishment que Lima y Belano tanto detestan. La mención de Paz es una manera de convocar intertextualmente a todo un cúmulo de autores que constituía en los años setenta al establishment literario mexicano y latinoamericano. Por tal razón, sabotear sus recitales era una forma de manifestar abiertamente su desacuerdo con aquellas poéticas predominantes y hegemónicas de entonces. En la realidad era igual. Carmen Boullosa, poeta joven en aquellos tiempos, tanto en la vida como en la novela en mención, decía que Bolaño se soltaba en discursos donde sustentaba su odio a Octavio Paz (423).

No obstante, la escena del encuentro entre Lima y Paz se constituye, de alguna manera, en una especie de oportunidad para limar asperezas, para fumar la pipa de la paz, y como una forma de que los líderes del real visceralismo y todos sus poetas adscritos se liberen del pesado y visceral yugo que los ata con una actitud anárquica y contestataria. Tal liberación o ruptura les permite, a partir de entonces, buscar y construir nuevos 
horizontes literarios o vitales. Se liberaban de ese yugo y podían seguir cargando, más como reliquia que como otra cosa, a sus poetas y escritores tutelares. Bien dan cuenta de ello las palabras de Rafael Barrios en uno de sus testimonios consignados en la segunda parte de la novela, recogido en el café Quito de la calle Bucarelli en el D.F., en 1977, apenas a un año de los viajes de Lima y Belano, aunque es bastante probable que su perorata sea apenas una broma, una alucinación, un manifiesto sobre la frustración y la duda, sobre el abismo, un lamento en el umbral del descreimiento poético, un grito de horror ante la inevitabilidad del aterrizaje forzoso a la realidad donde los poetas no son más que perros románticos y fracasados.

Qué hicimos los real visceralistas cuando se marcharon Ulises Lima y Arturo Belano: escritura automática, cadáveres exquisitos, performances de una sola persona y sin espectadores, contraintes, escritura a dos manos, a tres manos, escritura masturbatoria (con la derecha escribimos, con la izquierda nos masturbamos, o al revés si eres zurdo), madrigales, poemas-novela, sonetos cuya última palabra siempre es la misma, mensajes de sólo tres palabras escritos en las paredes («no puedo más», «Laura, te amo», etc.), diarios desmesurados, mail-poetry, projective verse, poesía conversacional, antipoesía, poesía concreta brasileña (escrita en portugués de diccionario), poemas en prosa policíacos (se cuenta con extrema economía una historia policial, la última frase la dilucida o no), parábolas, fábulas, teatro del absurdo, pop-art, haikús, epigramas (en realidad imitaciones o variaciones de Catulo, casi todas de Moctezuma Rodríguez), poesía-desperada (baladas del Oeste), poesía georgiana, poesía de la experiencia, poesía beat, apócrifos de bp-Nichol, de John Giorno, de John Cage (A Year from Monday), de Ted Berrigan, del hermano Antoninus, de Armand Schwerner (The Tablets), poesía letrista, caligramas, poesía eléctrica (Bulteau, Messagier), poesía sanguinaria (tres muertos como mínimo), poesía pornográfica (variantes heterosexual, homosexual y bisexual, independientemente de la inclinación particular del poeta), poemas apócrifos de los nadaístas colombianos, horazerianos del Perú, catalépticos de Uruguay, tzantzicos de Ecuador, caníbales brasileños, teatro Nô proletario... Incluso sacamos una revista... Nos movimos... Nos movimos... Hicimos todo lo que pudimos... Pero nada salió bien. (214)

Los artistas que aparecen en Un paseo por la literatura y en esta enumeración huidiza en Los detectives salvajes son apenas una muestra del lugar que la intertextualidad ocupa en la obra del escritor chileno, fortalecida ella, por supuesto, con las otras narraciones donde los escritores son los protagonistas frágiles o inexpugnables. Dice Álvaro Bisama que los libros de Bolaño "funcionan más como cajas de resonancia, como trampas borgianas, como laberintos de citas que sí conducen a alguna parte, más que como novelas perfectas, cerradas y acotadas" (80). En Bolaño, la intertextualidad tiene múltiples matices y puede ir de la intratextualidad o intertextualidad autárquica (o interna, como la denomina Lucien Dallenbach ${ }^{4}$ ) donde una obra establece un diálogo con sí

\footnotetext{
${ }^{4}$ Fernando de Toro, en su obra Semiótica del Teatro: del texto a la puesta en escena (2008) recuerda que "la noción misma de intertextualidad puede ser precisada y subdividida si diferenciamos distintas formas de operar de un inter-texto. Estas prácticas intertextuales, según Lucien Dallenbach, son las siguientes: intertextualidad general - las relaciones intertextuales entre textos de diferentes autores-; intertextualidad limitada — las relaciones intertextuales entre textos de un mismo autor-; intertextualidad externa - relación de un texto con otro texto-; intertextualidad interna - relación de un texto consigo
} 
misma, como en el caso de La literatura nazi en América, que se constituye en una especie de diccionario de autores que se conocen y se influyen entre sí, hasta la metatextualidad, entendida como un comentario a otro texto sin necesidad de citarlo. Por ejemplo, El gaucho insufrible sería, según el análisis hecho por Gustavo Faverón Patriau, una relectura y una reescritura de "El Sur", de Borges, principalmente, pero también de "El evangelio según San Marcos", del mismo autor, de "Carta a una señorita en París", de Cortázar, de "Ser polvo", de Santiago Dabove, de "Los conejos", de Juan Rodolfo Wilcock, de "Aballay", "Conejos" y "Caballo en el salitral", de Antonio Di Benedetto, de "Los padres de la patria", de Rodrigo Fresán (371-415).

Pero también puede ir hasta la hipertextualidad, que establece la relación de un texto con uno anterior, como se plantea en el inicio de Estrella distante, en una especie de prefacio atribuible a Roberto Bolaño en el que manifiesta, con la máscara del autortrascriptor, que es Arturo Belano el verdadero autor de dicha obra para la cual se basó en el capítulo final ("Ramírez Hoffman, el infame", es el título) de una novela previa de Bolaño: La literatura nazi en América. Y como si esto no fuera suficiente, se indica que dicho texto fue escrito en Blanes en un contexto donde estuvo siempre presente "el fantasma cada día más vivo de Pierre Menard." (Bolaño, Estrella distante 11) En esta misma categoría puede ubicarse la novela Amuleto, ya que su origen está en los testimonios de Auxilio Lacouture contenidos en la segunda parte de Los detectives salvajes. ${ }^{5}$

También es frecuente en Bolaño lo que el filólogo italiano Cesare Segre llama interdiscursividad, para referirse a la relación que un texto literario tiene con otras artes, casi un juego de miradas y de guiños, como cuando en 2666 se cuenta la historia de Edwin Johns, un pintor que decide cortarse su mano derecha para que, luego de llevarla a un taxidermista, fuera supuestamente la pieza clave de su obra pictórica maestra, concebida ésta como un espiral de autorretratos, aunque en el fondo quizá todo fue hecho por dinero. En ese ámbito de juegos y de guiños donde la vida se convierte o puede convertirse en una obra de arte, cabe destacar una frase de Liz Norton: "Recuerdo que una pareja, ambos muy altos y delgados, que miraban un cuadro, me miraron con extrema curiosidad, como si yo fuera una ex amante de Johns o un cuadro viviente (e inacabado) que de pronto se entera de la muerte de su pintor." (Bolaño 195)

mismo-y finalmente autotextualidad o mise en abîme" (74). El término mise en abîme (introducido por André Gide en 1893) hace referencia a un procedimiento heredado de la heráldica que consiste en reproducir, de forma reducida, parte de una obra en su propio interior. De Toro agrega que las diferenciaciones de intertextualidad antes planteadas son necesarias porque permiten precisar el funcionamiento de los inter-textos. "No obstante, debemos señalar que estas categorías funcionan de una forma interrelacionada: por ejemplo, tanto la intertextualidad general como la limitada son intertextualidades externas. Por otra parte, la autotextualidad es una intertextualidad interna. La razón de separar intertextualidad interna de autotextualidad está en que no toda intertextualidad es autotextualidad. Podemos tener un texto que se refiere a otros textos o a trozos de sí mismo" (74).

${ }^{5}$ Para denominar este rehacer con base en textos anteriores, tal como sucede en la ampliación de episodios que dan pie a Estrella distante y Amuleto con base en historias contenidas en La literatura nazi en América y Los detectives salvajes, respectivamente, el crítico español Ignacio Echevarría retoma el término fractalidad, del matemático Benoît Mandelbrot, con el cual se designa "la propiedad que ciertas figuras espaciales compuestas por una multitud de elementos tienen de preservar el mismo aspecto, cualquiera sea la escala en que se observa" (432 y 433). 
Por supuesto, otras obras de Bolaño están construidas sobre el mundo de la intertextualidad. Monsieur Pain es la historia de un médico mesmerista que atiende en el lecho de muerte a César Vallejo, sin saber de la grandeza de su paciente. En Nocturno de Chile, un connotado crítico literario de derechas, sacerdote cercano al Opus Dei y profesor de marxismo de Pinochet, se encuentra acorralado por sus propios pensamientos y reflexiones, y quizás remordimientos, en una noche lluviosa y centelleante en que imagina y siente que un joven envejecido (que puede ser él mismo o un escritor como Bolaño) lo increpa sin piedad. Por Nocturno de Chile pasa Neruda y pasan los poetas e intelectuales que asisten a una elegante tertulia de una casa donde departen alegremente mientras en el sótano torturan hasta morir a personas no afines con el régimen. Y pasa por esta novela, también, toda una generación que esconde sus culpas e intenta olvidarlas en sus cotidianos trabajos, intelectuales o físicos, en su ir y venir, pero siempre desentendiéndose de una realidad que carcome por dentro y hace emitir gritos que nadie escucha, como una inapagable "tormenta de mierda", que era el título que Bolaño quería para esta narración.

... y luego volví a Chile, porque yo siempre vuelvo, sino no sería ese chileno resplandeciente, y seguí con mis reseñas en el periódico, con mis críticas que pedían a gritos, apenas el lector distraído rascaba un poco en su superficie, una actitud diferente frente a la cultura, mis críticas que pedían a gritos, que suplicaban incluso, la lectura de los griegos y de los latinos, la lectura de los provenzales, la lectura del dolce stil nuovo, la lectura de los clásicos de España y Francia e Inglaterra, ¡más cultura!, ¡más cultura!, la lectura de Whitman y de Pound y de Eliot, la lectura de Neruda y Borges y Vallejo, la lectura de Víctor Hugo, por Dios, y la de Tolstoi, y me desgañitaba ufano en el desierto... (122-123)

Pero donde la intertextualidad bolañiana y la metaliteratura se hacen más precisas es en Los detectives salvajes. Allí se recurre a la relación transtextual, en los términos en que la asume Genette, pero también en las variables o prácticas intertextuales que Lucien Dallenbach propone precisar y que fueron mencionadas antes: intertextualidad general, limitada, externa e interna. Y se hace necesario recurrir a ellas porque así lo requiere una historia donde los personajes principales y secundarios son en su mayoría poetas y asisten a tertulias literarias, o han fundado o pertenecen a un grupo literario que se bate a muerte, metafóricamente, con la literatura y los autores del establishment. De otro lado, puede hacerse una lectura de intertextualidad interna cuando se alude al universo de los escritores-personajes que construyen su propio catálogo literario, real o proyectado, o independientemente de que unos publiquen y otros parezcan mudos o se limiten sólo a escuchar y a proyectar lo que quisieran escribir pero no pueden, o incluso a sabiendas de que de otros escritores no se conozca literalmente sus escritos aunque alguien cite alguno de ellos como "el mejor poema que jamás había escuchado". Y también se presenta la transtextualidad, con el ropaje de la hipertextualidad, en la base fundacional de la novela, cuando Belano y Lima buscan a Cesárea Tinajero, escritora alguna vez vanguardista de la que sólo conocen una poesía visual, y que cuando la encuentran se ha convertido en una especie de "buque de guerra fantasma" (Bolaño, Los detectives salvajes 603). Tal hipertextualidad es la que, en el fondo, hace detectives a estos dos veteranos de las guerras floridas, de la misma manera como después ellos son los personajes buscados en los 
entresijos de la memoria de quienes alguna vez los conocieron y que se han ido diluyendo en los placeres, fracasos o desencantos de la pequeña burguesía.

Más allá de las novelas y la poesía, también en los relatos hay elementos transtextuales y para dar cuenta de ello basta citar tres ejemplos. "Sensini" es un relato donde un veterano escritor argentino, experto en ganar premios literarios de poca monta, intercambia misivas con un escritor mucho más joven, cómplice epistolar en esa misión de sobrevivir siendo pistolero, cazarrecompensas o cazador de cabelleras. "Sus ingresos provenían de unos vagos trabajos editoriales (creo que corregía traducciones) y de los cuentos que salían a pelear a provincias" (Bolaño, Llamadas telefónicas 21), recuerda el joven narrador. También el mundo literario de la Francia de la Segunda Guerra es el contexto del relato "Henry Simón Leprince", donde un escritor fracasado afín a la Resistencia comprende al final que los malos escritores ocupan también un lugar en la pirámide literaria, bien sea como lectores o como escuderos. Otro relato, "Enrique Martín", contenido en Llamadas telefónicas, como los dos anteriormente citados, es protagonizado por un poeta, amigo de Arturo Belano, que opta por un suicidio misterioso que a éste le parece como "el billete de regreso al planeta natal." (49)

Así las cosas, siendo la literatura el tema angular de la obra de Bolaño parece inevitable la aparición de referencias a autores reales o ficticios, y parece inevitable que los personajes se muevan indistintamente en los escenarios de unos y de otros, franqueando fronteras como en un intenso viaje. Por esa razón, Ulises Lima puede encontrarse con Octavio Paz pero también con Arturo Belano, y por eso, este escritor chileno puede escribir en la casa de Roberto Bolaño en Blanes la novela Estrella distante, donde el poeta-asesino que en La literatura nazi en América se llamaba Ramírez Hoffman o Emilio Stevens, ahora se llama Carlos Wieder o Alberto Ruiz Tagle. De la misma manera, el sacerdote de Nocturno de Chile que se llama Sebastián Urrutia Lacroix firma sus críticas con el seudónimo de H. Ibacache, pero su referente en la realidad se llamaba José Miguel Ibáñez Langlois y firmaba como Ignacio Valente. O como los muchos nombres que tiene Benno von Archimboldi, cuya historia queda trunca cuando va a viajar al norte de México donde la muerte acecha impunemente a las mujeres de Santa Teresa, trasunto de Ciudad Juárez.

Es evidente que, en Bolaño, la cuestión no es de nombres, no. La cuestión es de viajes, de exilios fuera y dentro de sí, la cuestión es tanto de reconocimientos como de desconocimientos frente a unos espejos que suelen estar rotos y en donde sólo se puede leer las imágenes o reconstruirlas a través de las lecturas de otros espejos rotos y de sus esquirlas hechas añicos. Y esos espejos rotos bien pueden estar contenidos en otros libros, en otros escritores, en otras ciudades, en otras realidades, pero que en el fondo siempre terminan siendo uno solo. El espejo roto de sí mismo.

\section{El ir y venir idiomático: el lenguaje de la literatura}

Tampoco hay barreras idiomáticas para los personajes de Bolaño. Ellos se mueven por el mundo como si en todos los lugares se hablara el mismo idioma. Porque, para el escritor chileno, así es. Benno von Archimboldi recorre el mundo sin que jamás tenga un tropiezo comunicativo por cuenta del idioma, ni lo tiene Oscar Fate, un periodista afroamericano de la revista "Amanecer negro", cuando traspasa la frontera para ir al 
estado de Sonora a cubrir una pelea de boxeo y se encuentra con la brutalidad de los asesinatos en serie de mujeres en Santa Teresa. Ni lo tiene Anne Moore en su periplo por el mundo, ni Arturo Belano en Europa o África, ni los demás personajes de novelas y relatos. Y no se necesita nada más porque, bien se puede decir con Joanna Silvestri, que "todos somos fantasmas, que todos hemos entrado demasiado pronto en las películas de los fantasmas" (Bolaño, Llamadas telefónicas 174), y ellos hablan un sólo idioma. En estricto sentido, esa característica en la obra del escritor chileno es una huella más de su desterritorialización, tal como la conciben Deleuze y Guattari (2004), o de lo queSteiner llama extraterritorialidad (2009). Viene bien, aquí, citar a Ignacio Echevarría, un crítico muy cercano a Roberto Bolaño, quien, incluso más allá del idioma, relaciona extraterritorialidad, globalización y exilio retomando a George Steiner quien sí tenía en cuenta en sus análisis el nomadismo lingüístico practicado por Nabokov y Beckett, quienes escribieron sus obras en un idioma que no era para ellos el materno.

Aunque Steiner apenas lo bosquejaba y lo hacía con bastante imprecisión, esta categoría — la de extraterritorialidad — ha ganado connotaciones cada vez más útiles. Sin necesidad de circunscribirla al ámbito estrictamente idiomático, lo cierto es que en el contexto del nuevo internacionalismo cultural, bajo los efectos globalizadores de la cultura de masas, la noción de extraterritorialidad subvierte la ya más anticuada y más complaciente de cosmopolitismo para sugerir aquellos aspectos de la literatura moderna en que esta se perfila, en palabras del propio Steiner, como "una estrategia de exilio permanente". (438)

Por supuesto que no hay en Roberto Bolaño el nomadismo lingüístico en el sentido del de Nabokov y Beckett, aunque sí lo hay en la itinerancia global de los personajes de sus obras. Pero eso el lector debe suponerlo, porque no siempre tendrán un cuadro, una descripción o un diálogo que lo evidencien concretamente, como cuando Heimito Künst y Ulises Lima están confinados en una cárcel de Beersheba, en Israel: "Escuché que el buen Ulises hablaba en inglés, pero no entendí lo que decía. Los árabes hablaron en inglés, pero no entendí lo que decían. El buen Ulises se rio. Los árabes se rieron. Entendí sus risas y dejé de resoplar." (Bolaño, Los detectives salvajes 306) O como cuando Hitler se hace fotos con Edelmira Thompson de Mendiluce y sus hijos: "El futuro Führer del Reich causa en la poetisa argentina una gran impresión. Antes de despedirse le regala algunos de sus libros y un ejemplar de lujo del Martín Fierro, obsequios que Hitler agradece calurosamente obligándola a improvisar una traducción al alemán allí mismo, cosa que no sin dificultad consiguen entre Edelmira y Carazzone." (Bolaño, La literatura nazi... 16) O cuando aparece el poema de Rimbaud que Ulises Lima recita en francés, a manera de adivinanza, para los amigos un tanto ebrios que departen con él en una discoteca. No obstante estas citas puntuales - en la primera es más importante destacar que sea el latinoamericano y no el europeo el que hable el idioma universal por antonomasia, hecho que se puede leer como otra huella de ruptura de Bolaño con la ambivalencia centroperiferia - el nomadismo lingüístico en la obra de Bolaño fluye con tal naturalidad que no se hace necesario mencionarlo repetidamente en el desarrollo de su narrativa. De igual modo puede ser considerado, también, como otra forma del exilio. 
Si bien un desapego a la realidad multilingüística y a los desencuentros que en ella se presentan puede afectar de algún modo, aunque no en exceso, la verosimilitud de alguna obra puntual del escritor chileno, esto no incide seriamente en el devenir narrativo general porque más que una falta de "deber de cuidado" o de carpintería literaria, dicha omisión se constituye en un elemento que confirma en Bolaño una esencia desterritorializada que tiene mucho que ver con la ruptura de fronteras. Es muy posible que para Bolaño no exista algo que se llame "Torre de Babel" y menos en un contexto donde los personajes son escritores que han asimilado una tradición literaria universal (ficticia o real) y que muy seguramente han utilizado en ello la lengua original de los artistas. Una anotación en el diario de Juan García Madero, que más parece una ironía, una burla o una ingenuidad, puede confirmarlo, como confirma, al tiempo, el sutil sentido del humor de Bolaño:

Los libros que llevaba Ulises Lima eran:

Manifeste electrique aux paupieres de jupes, de Michel Bulteau, Matthieu Messagier, Jean-Jacques Faussot, Jean-Jacques N'Guyen That, Gyl Bert RamSoutrenom F.M., entre otros poetas del movimiento eléctrico, nuestros pares de Francia (supongo).

Sang de satin, de Michel Bulteau.

Nord d'été naître opaque, de Mathieu Messagier.

Los libros que llevaba Arturo Belano eran:

Le parfait criminel, de Alan Jouffroy.

La pays oú tout est permis, de Sophie Podolski.

Cent mille milliards de poèmes, de Raymond Queneau. (Este último estaba fotocopiado y los cortes horizontales que exhibía la fotocopia más el desgaste propio de un libro manoseado en exceso, lo convertían en una especie de asombrada flor de papel, con los pétalos erizados hacia los cuatro puntos cardinales.)

Más tarde nos encontramos con Ernesto San Epifanio, que también llevaba tres libros. Le pedí que me los dejara anotar. Eran estos:

Little Johnny's Confession, de Brian Patten.

Tonight at Noon, de Adrian Henry.

The Lost Fire Brigade, de Spike Hawkins. (Bolaño, Los detectives salvajes 2829).

Ciertos o imaginados, para poder moverse entre fronteras es imprescindible, según Bolaño, que el escritor verdadero tenga sólo un pasaporte: el de la calidad de la escritura. Y las obras de esos buenos escritores son capaces de resistirse aun a las malas e inevitables traducciones y de resistirse a los olvidos.

¿Cómo reconocer una obra de arte? ¿Cómo separarla, aunque sea sólo un momento, de su aparato crítico, de sus exégetas, de sus incansables plagiarios, de sus ninguneadores, de su final destino de soledad? Es fácil. Hay que traducirla. Que el traductor no sea una lumbrera. Hay que arrancarle páginas al azar. Hay que dejarla tirada en un desván. Si después de todo esto aparece un joven y la lee, y tras leerla la hace suya, y le es fiel (o infiel, qué más da) y la reinterpreta y la acompaña en su viaje a los límites y ambos se enriquecen y el joven añade un gramo de valor a su valor natural, estamos ante algo, una máquina o un libro, capaz de hablar a todos los seres humanos: 
no un campo labrado sino una montaña, no la imagen del bosque oscuro sino el bosque oscuro, no una bandada de pájaros sino el Ruiseñor. (Bolaño, Entre paréntesis 223-224)

Definitivamente, y pese a los muchos idiomas, para Bolaño no existe la torre de Babel.

\section{Referencias}

Bisama, Álvaro. "Todos somos monstruos", en Territorios en fuga. Estudios críticos sobre la obra de Roberto Bolaño (Espinosa, Patricia). Santiago de Chile: Frasis Editores, 2003. Impreso.

Bolaño, Roberto. Tres. Barcelona: Acantilado, 2000. Impreso.

Bolaño, Roberto. Estrella distante. Barcelona: Anagrama, 2003a. Impreso.

Bolaño, Roberto. Llamadas telefónicas. Barcelona: Anagrama, 2003b. Impreso.

Bolaño, Roberto. El gaucho insufrible. Barcelona: Anagrama, 2003c. Impreso.

Bolaño, Roberto. Entre paréntesis. Barcelona: Anagrama, 2004. Impreso.

Bolaño, Roberto. Putas asesinas. Barcelona: Anagrama, 2005a. Impreso.

Bolaño, Roberto. La literatura nazi en América. Barcelona: Seix Barral, 2005b. Impreso.

Bolaño, Roberto. 2666. Barcelona: Anagrama, 2007a. Impreso.

Bolaño, Roberto. Monsieur Pain. Barcelona: Anagrama, 2007b. Impreso.

Bolaño, Roberto. Amuleto. Barcelona: Anagrama, 2007c. Impreso.

Bolaño, Roberto. Nocturno de Chile. Barcelona: Anagrama, 2007d. Impreso.

Bolaño, Roberto. Los detectives salvajes. Barcelona: Anagrama, 2007e. Impreso.

Boullosa, Carmen. El agitador y las fiestas, en Bolaño Salvaje (ed. Paz Soldán, Edmundo y Faverón Patriau, Gustavo). Barcelona: Candaya, 2008. Impreso.

Braithwaite, Andrés. Bolaño por sí mismo, entrevistas escogidas. Santiago de Chile: Ediciones Universidad Diego Portales, 2006. Impreso.

Camus, Albert. El primer hombre. Madrid: Tusquets Editores, 1994. Impreso.

Certeau, Michel de. La invención de lo cotidiano. México: Universidad Iberoamericana, 1996. Impreso.

De Toro, Fernando. Semiótica del teatro: del texto a la puesta en escena. Buenos Aires: Gaberna, 2008. Impreso.

Deleuze, Gilles, y Guattari, Félix. Mil mesetas. Capitalismo y esquizofrenia. Valencia: Pretextos, 2004. Impreso. 
Echevarría, Ignacio. "Bolaño extraterritorial”, en Bolaño Salvaje (ed. Paz Soldán, Edmundo y Faverón Patriau, Gustavo). Barcelona: Candaya, 2008. Impreso.

Espinosa, Patricia. “Tres de Roberto Bolaño: el crac de la modernidad”, en Territorios en fuga. Estudios críticos sobre la obra de Roberto Bolaño (Espinosa, Patricia). Santiago de Chile: Frasis Editores, 2003. Impreso.

Franz, Carlos. "Una tristeza insoportable. Ocho hipótesis sobre la mela-cholé de B”, en Bolaño Salvaje (ed. Paz Soldán, Edmundo y Faverón Patriau, Gustavo). Barcelona: Candaya, 2008. Impreso.

Faverón Patriau, Gustavo. "El rehacedor: El gaucho insufrible y el ingreso de Bolaño en la tradición argentina”. en Bolaño Salvaje (ed. Paz Soldán, Edmundo y Faverón Patriau, Gustavo). Barcelona: Candaya, 2008. Impreso.

Genette, Gérard. Palimpsestos, la literatura en segundo grado. Madrid: Taurus, 2008. Impreso.

Kristeva, Julia. Semiótica 1. Madrid: Editorial Espiral Fundamentos, 1978. Impreso.

Saramago, José. El cuaderno del año del Nobel. Barcelona: Alfaguara, 2018. Impreso.

Steiner, George. Extraterritorial: ensayos sobre la literatura y la revolución del lenguaje. Buenos Aires: Adriana Hidalgo, 2009. Impreso.

Valencia, Leonardo. El síndrome de Falcón. Guayaquil: Paradiso Editores, 2008. Impreso. 